\title{
Movement of Saltwater Border of Modaomen Channel in Dry Season with Different Runoff
}

\author{
Xinying Chen ${ }^{\mathrm{a}}$, Yun Bao ${ }^{\mathrm{b}}$ \\ Department of Mechanics, Sun Yet-sen University, Guangzhou, China 510275 \\ axinyingsky@163.com, ${ }^{b}$ stsby@mail.sysu.edu.cn
}

Keywords: The Modaomen channel; Salinity intrusion; Movement of saltwater border

Abstract: With the saltwater border map method, the saltwater border map along Modaomen channel in dry season of 2014-2015 year is drawn and the time series of the 0.5\% saltwater border is obtained. The movement of the saltwater border is discussed. There are two phases with different amount of upstream runoff in the period. The movement of the saltwater border in two phase is discussed and compared with that in previous dry or wet years. The results show that, the law of saltwater border in the phase with lower runoff is similar to that in the previous dry years, and the law of saltwater border in the phase with higher runoff is similar to that in the previous wet years. It indicates the fact that, the relationship between runoff and saltwater border is basically invariant.

\section{Introduction}

Salinity intrusion is a common natural phenomenon in estuaries, which is one of the key issues in the research of estuarine. The inland study of saltwater intrusion began in1960s. X. Tian ${ }^{[1]}$ summarized the studies at home and abroad of saltwater intrusion in Pearl River Estuarine. P. Wen et al ${ }^{[2]}$ make a series of studies of saltwater intrusion in Modaomen channel. Z. Qi and Y. Bao ${ }^{[3][4]}$ put forward the saltwater border map method, which analysis the saltwater with a field instead of isolated station, and discussed the law of saltwater border along the Modaomen channel.

In this paper, The movement of saltwater border along Modaomen channel in dry season of 2014-2015 year is discussed. According to saltwater border with semi-month periodicity from 2007 to $2011^{[5]}$, the saltwater border in 2014-2015 is segmental analyzed and compared.

\section{Research region and methods}

The region focused in this work is the Modaomen channel that at the downstream Xijiang River. The Modaomen channel is located in central-southern Guangdong Province that runs north from Baiqintou of Xinhui District, south via Zhuhai City into the sea. The Modaomen channel is nearly straight that could be simplified as a one-dimensional model.

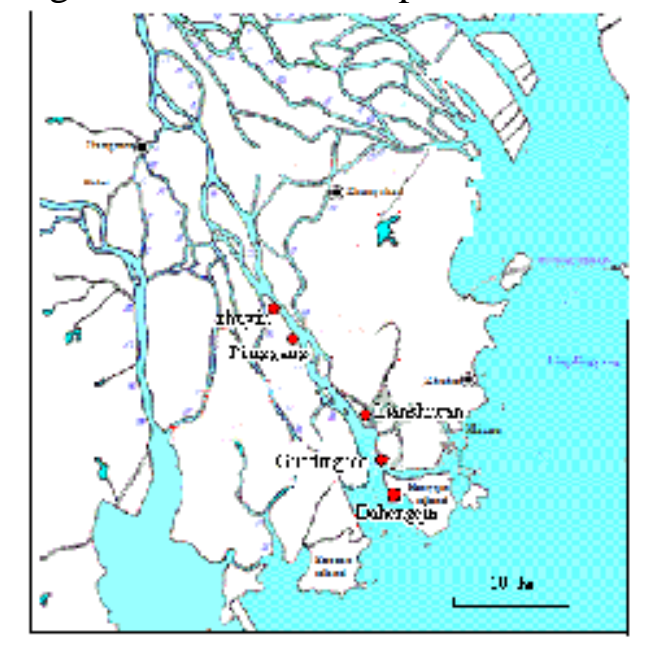

Fig. 1 the station along Modaomen channel

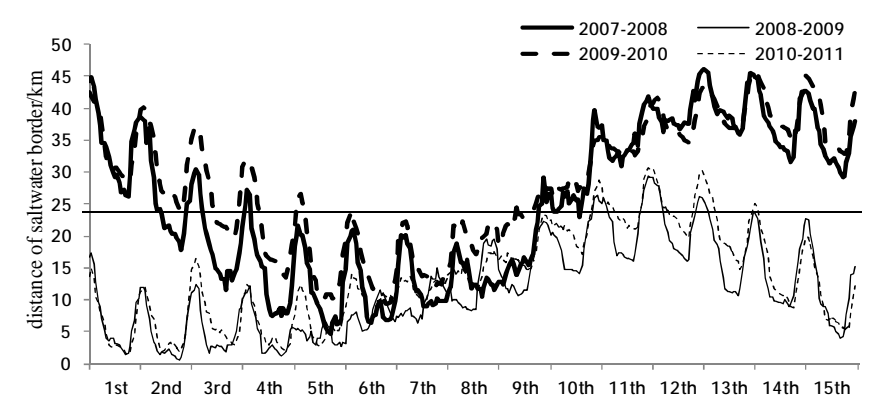

Fig. 2 the time series of $0.5 \%$ saltwater border with semi-month periodicity from 2007 to 2011 by trichotomy ${ }^{[5]}$ 
The main research method in this work is saltwater border map method. The hydrological station(shown in Fig. 1), Dahengqin, Guadingjiao, Lianshiwan, Pinggang, Zhuyin, in the Modaomen channel is as far as $1.9 \mathrm{~km}, 11 \mathrm{~km}, 18.7 \mathrm{~km}, 34.8 \mathrm{~km}$ and $40.8 \mathrm{~km}$ to the sea respectively. Uses Lagrange interpolation along the Modaomen channel with the data from this five stations, the saltwater border map is drawn, which shows the one-dimensional distribution of saltwater along the Modaomen channel. In this work, the Guadingjiao station is defined as origin with positive direction upstream. The lunar calendar is used in this work and the description is simplified. (for instance, describe the twenty-third day of the ninth lunar month as 9-23, describe the dry season from 2014 to 2015 as 2014-2015.)

With the saltwater border map method, Y. Bao et $\mathrm{al}^{[5]}$ discussed the law of $0.5 \%$ saltwater border with semi-month periodicity by trichotomy in the dry season of the four years (include dry years and wet years) from 2007 to 2011,which is shown in Fig. 2. The abscissa represents the date from first to fifteenth day of the lunar calendar. The ordinate represents the distance of saltwater border. The lines show the laws of saltwater border with semi-month periodicity. The horizontal black line shows the position of Pinggang hydrological station, which is a landmark of the salinity intrusion disaster.

According to the data of runoff in upstream Pearl River, 2007-2008 and 2009-2010 are dry years while 2008-2009 and 2010-2011 are wet years. Fig. 2 shows that, the movement of 0.5\%o saltwater borders with semi-month periodicity has typical laws and that is obviously different between the dry years and wet years. The furthest distance of saltwater border is $45 \mathrm{~km}$ in dry years while $30 \mathrm{~km}$ in wet years. There are six consecutive days in dry years that the saltwater border upper the Pinggang station while only several hours in wet years.

\section{The movement of Saltwater border in 2014-2015}

The time series of hourly distance of the 0.5\% saltwater border in the dry season of 2014-2015 year are obtained by saltwater border map method. Fig. 3 shows the time series of hourly saltwater border, the hourly tide level in Sanzao and the daily runoff in Wuzhou and Shijiao.

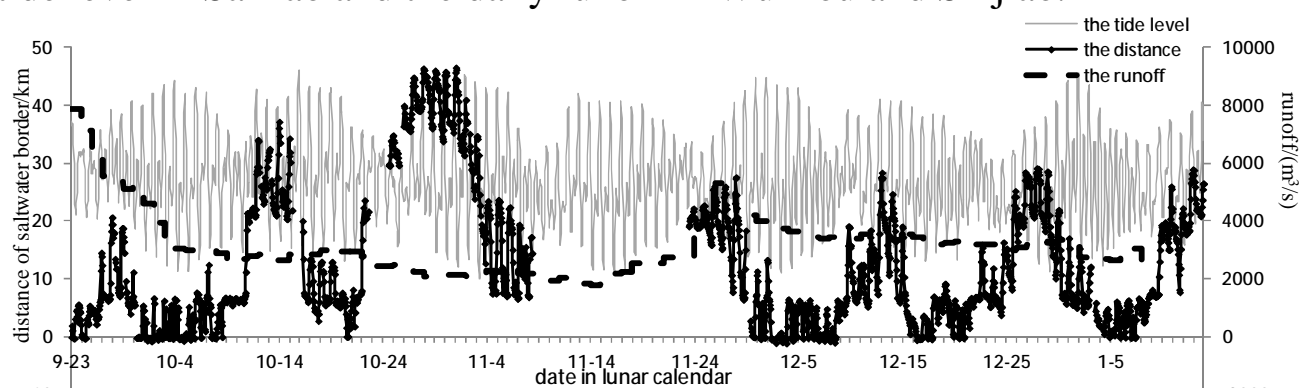

Fig. 3 The time series of saltwater, tide level and runoff in the dry season of 2014-2015 year

In Fig. 3, the abscissa represents the date(from9-23 to next 1-13) of the lunar calendar. The dotted line shows the distance of saltwater border, which can be read on the left ordinate. The dashed line shows the runoff, which can be read on the right ordinate. The gray solid line shows the tide level. The salinity data from11-9 to 11-22 are missing.

The movement of saltwater border possess well daily and semi-month periodicity in the dry season of 2014-2015 year. From 9-23 to 10-2, the furthest distance of saltwater border is 20km with a large runoff. On 10-3, the dry season is coming with the runoff of around $3000 \mathrm{~m}^{3} / \mathrm{s}$. Saltwater border move further and the furthest distance is $37 \mathrm{~km}$. From $10-21$, the runoff is around $2300 \mathrm{~m}^{3} / \mathrm{s}$. The saltwater sail further upstream with both the low runoff and the northeasterly winds and the furthest distance of saltwater border is $46 \mathrm{~km}$. On the $11-23$, the runoff is around $3300 \mathrm{~m}^{3} / \mathrm{s}$ with a sudden growth. The furthest distance of saltwater border decreases into $29 \mathrm{~km}$.

\section{Segmental comparison}

Based on the data of runoff, the dry season of 2014-2015 year is divided into two phases. The first phase is from $10-24$ to $11-8$. The value of runoff in the first phase is less than $2500 \mathrm{~m}^{3} / \mathrm{s}$, which is close 
to that in dry years. The second phase is from 11-23 to next 1-13. The value of runoff in the second phase is more than $3000 \mathrm{~m}^{3} / \mathrm{s}$, which is close to that in wet years.

In the first phase, the movement of saltwater border is shown in Fig. 4.

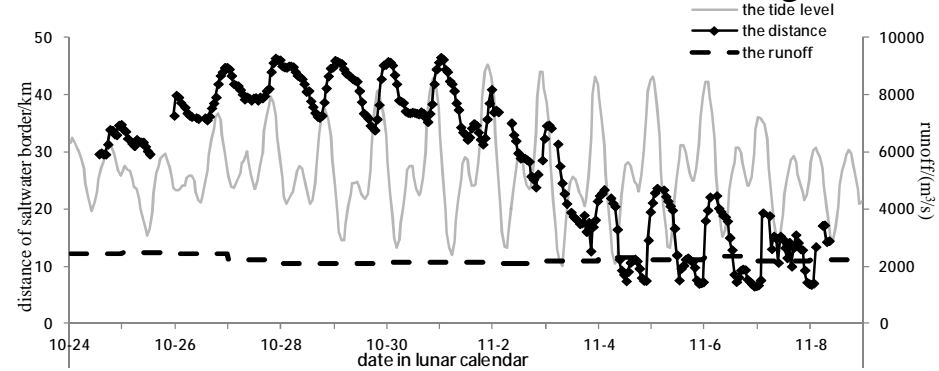

Fig. 4 the time series of saltwater border, tide level and runoff in the first phase

In the first phase, The distance of saltwater border is around 30km on 10-24 (neap tide). There is around $5 \mathrm{~km}$ upstream advancing in total with $5-10 \mathrm{~km}$ of vibration everyday. the furthest distance in this phase is $46 \mathrm{~km}$ that it is reached on $10-28$. Next, saltwater border vibrate for four days in the upstream with around 10km vibration everyday. After 11-1 (spring tide), saltwater border move downstream at a speed of around $6 \mathrm{~km}$ per day. Three days later, the distance of saltwater border is less than $25 \mathrm{~km}$ and saltwater border vibrate in a range of 7 to $24 \mathrm{~km}$.

Fig. 5 shows the comparison of the law of saltwater border in the first phase (fifteen days in total) and saltwater border with semi-month periodicity in the previous dry years ${ }^{[5]}$.

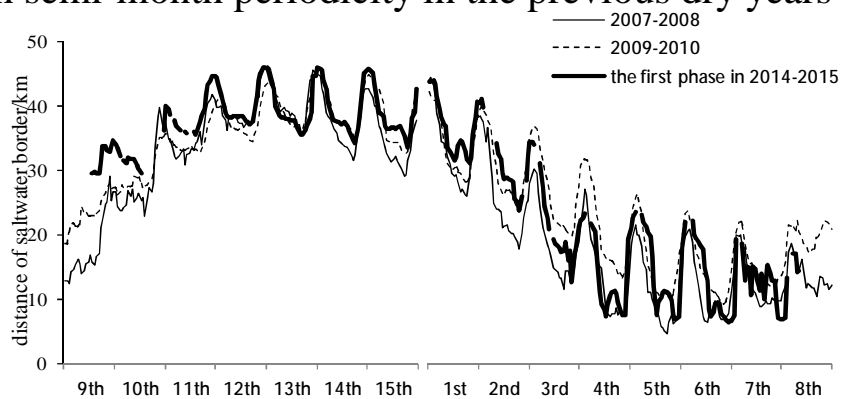

Fig. 5 the comparison between saltwater border in the first phase and that in the previous dry years

In Fig. 5, the abscissa represents the date from $9^{\text {th }}$ to next $8^{\text {th }}$ (the same as the order in the first phase)of the lunar calendar. The lines show the distance of saltwater border in the previous dry years and the first phase of 2014-2015. On $9^{\text {th }}$ (neap-spring tide), saltwater border in the first phase is $5 \mathrm{~km}$ further than previous. With the advent of the spring tide, three lines are more and more close. From $13^{\text {th }}$ to next $8^{\text {th }}$, the line of saltwater border in the three period is similar. In conclusion, saltwater border in the first phase of 2014-2015 is slightly further than the previous from $9^{\text {th }}$ to $10^{\text {th }}$ while basically corresponding in the other day.

In the second phase, the movement of saltwater border is shown in Fig. 6.

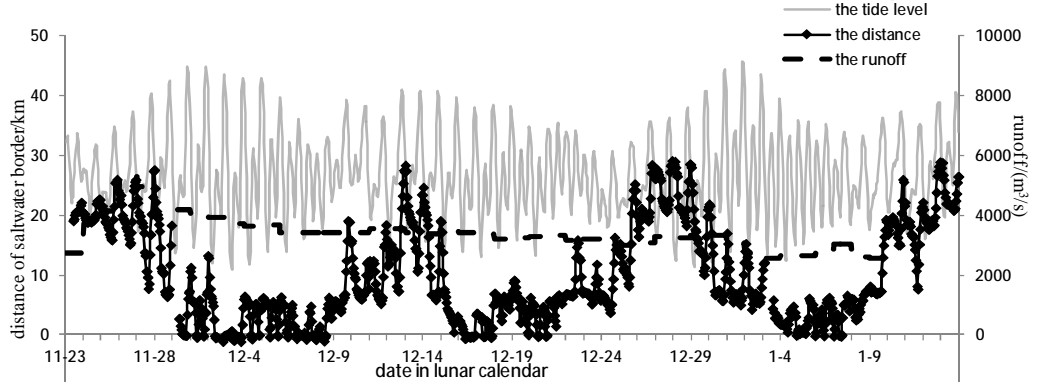

Fig. 6 the time series of saltwater border, tide level and runoff in the second phase

In the second phase, the time series of saltwater border possess well semi-month periodicity according to the result of periodicity analysis. Saltwater border move between $0 \mathrm{~km}$ to $30 \mathrm{~km}$ in the three cycles. On 12-9 (after neap-tide), saltwater border move upstream with a vibration from $6 \mathrm{~km}$. It reaches the furthest, $28 \mathrm{~km}$, on 12-13. Then it moves downstream immediately. Saltwater border move downstream at around $18 \mathrm{~km}$ and then move upstream at around $14 \mathrm{~km}$. On $12-15$, saltwater border 
fallback to the Guadingjiao station and vibrate at a range of 0-9km until next sail upstream. Saltwater border in other cycle has similar laws.

With the method of trichotomy, the semi-month periodicity time series of saltwater border is obtained. The comparison for it between this phase and the previous wet years ${ }^{[5]}$ is shown in Fig. 7 .

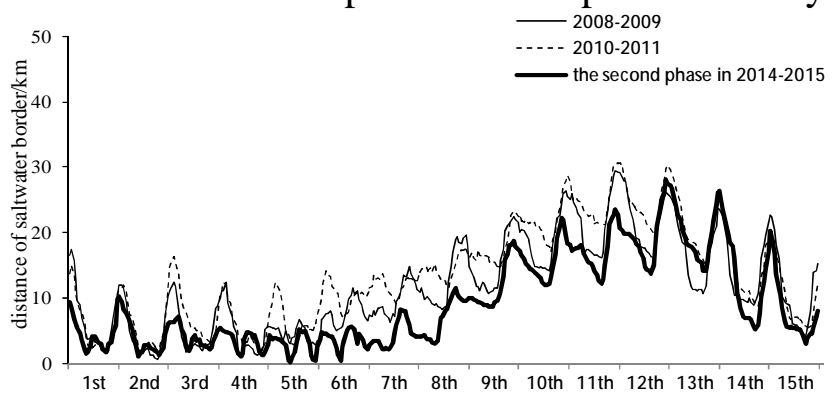

Fig. 7 the comparison between saltwater border in the second phase and that in the pervious wet years

In Fig. 7, the lines show the distance of saltwater border in the previous wet years and the second phase of 2014-2015. From $2^{\text {nd }}$ to $4^{\text {th }}$, the law nearby daily upstream point in the second phase is around $5 \mathrm{~km}$ lower than previous. From $6^{\text {th }}$ to $12^{\text {th }}$, the law in the second phase is $0-5 \mathrm{~km}$ lower than previous. The rest of the time, the law is similar. In conclusion, the distance of saltwater in the second phase of 2014-2015 is slightly lower than the previous wet years during the period with neap tide while basically corresponding in the other time.

\section{Conclusions}

In this paper, the law of saltwater border along the Modaomen channel in the dry season of 2014-2015 year is discussed with the method of saltwater border map. According to the time series of saltwater border, tide level and runoff in the period, the movement of saltwater border possess well daily and semi-month periodicity and it well response to different runoff. As runoff changes greatly in 2014-2015, the dry season of this year is divided into two phase with different amount of runoff that closed to the pervious dry or wet years. The law of saltwater border with semi-moth periodicity in this two phase is compared with that in previous dry and wet years respectively. It shows that, the law of saltwater border in the first phase with lower runoff is similar to that in the previous dry years, and the law in the second phase with higher runoff is similar to that in the previous wet years. In conclusion, the response by the movement of saltwater border to different value of runoff is barely changed.

\section{Acknowledgements}

The data in this work is provided by Pearl Ricer Water Resources Commission of the Ministry of Water Resources.

\section{References}

[1] X. Tian, Advance in Earth Sciences, Vol.9(2), 29-34, 1994(In Chinese)

[2] P. Wen, X. Chen, B. Liu, X. Yang, Journal of China Hydrology, Vol.27(03), 65-67, 2007(In Chinese)

[3] Z. Qi, Y. Bao, Vol.7(04), 61-65, 2009(In Chinese)

[4] Y. Bao, J. Liu, J. Ren, W. Xu, Z. Qi, Science in China Press. G, Vol.39(10), 1527-1534, 2009(In Chinese)

[5] Y. Bao, Y. Huang, J. Lin, Chinese Journal of Hydrodynamics. A, Vol.27(5), 2012(In Chinese) 